\title{
Polymorphonuclear leucocytes consume oxygen in sputum from chronic Pseudomonas aeruginosa pneumonia in cystic fibrosis
}

\author{
M Kolpen, ${ }^{1}$ C R Hansen, ${ }^{2}$ T Bjarnsholt, ${ }^{1}$ C Moser, ${ }^{1}$ L D Christensen, ${ }^{3}$ M van Gennip, ${ }^{3}$

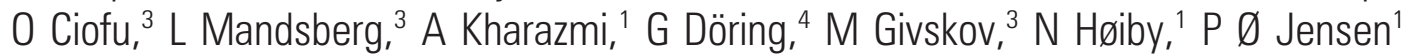

- Additional figures are published online only at http:// thorax.bmj.com/content/vol65/ issue1

${ }^{1}$ Department of Clinical Microbiology, Rigshospitalet, Copenhagen, Denmark;

${ }^{2}$ Copenhagen CF Center, Rigshospitalet, Copenhagen, Denmark; ${ }^{3}$ Institute of International Health,

Immunology, and Microbiology, University of Copenhagen,

Copenhagen, Denmark;

${ }^{4}$ Institute of Medical

Microbiology and Hygiene,

University of Tübingen,

Tübingen, Germany

Correspondence to:

Dr P $\varnothing$ Jensen, Department of Clinical Microbiology, Juliane

Mariesvej 22, Rigshospitalet, 2100 Copenhagen, Denmark; pojensendk@yahoo.dk

Received 6 March 2009 Accepted 29 September 2009 Published Online First

21 October 2009

\begin{abstract}
Background: Chronic lung infection with Pseudomonas aeruginosa is the most severe complication for patients with cystic fibrosis (CF). This infection is characterised by endobronchial mucoid biofilms surrounded by numerous polymorphonuclear leucocytes (PMNs). The mucoid phenotype offers protection against the PMNs, which are in general assumed to mount an active respiratory burst leading to lung tissue deterioration. An ongoing respiratory burst by the PMNs has, however, not been demonstrated previously in endobronchial secretions from chronically infected patients with CF.
\end{abstract}

Objective: Based on the accumulating evidence for depletion of molecular oxygen $\left(\mathrm{O}_{2}\right)$ in the mucus in infected CF bronchi, it was hypothesised that the $\mathrm{O}_{2}$ depletion in the mucus in infected CF bronchi may be accelerated by the respiratory burst of the PMNs due to the reduction of $\mathrm{O}_{2}$ to the superoxide anion $\left(\mathrm{O}_{2}^{-}\right)$by the phagocyte NADPH oxidase (Phox).

Methods: Methods were established to isolate the $\mathrm{O}_{2}$ consumption by the respiratory burst from aerobic respiration in freshly expectorated sputum from chronically infected patients with CF.

Results: Inhibition of the Phox with diphenylene iodonium (DPI) delayed $\mathrm{O}_{2}$ depletion, nearly abolished staining of $\mathrm{O}_{2}^{-}$-producing PMNs with hydroethidine and inhibited the rapid luminol-enhanced chemiluminescence in sputum. Furthermore, the total $\mathrm{O}_{2}$ consumption was correlated to the concentration of PMNs in the sputum samples.

Conclusion: The results demonstrate that CF sputum contains PMNs with an active consumption of $\mathrm{O}_{2}$ for $\mathrm{O}_{2}^{-}$ production and suggest that the respiratory burst is ongoing and causes accelerated $\mathrm{O}_{2}$ depletion due to formation of $\mathrm{O}_{2}^{-}$in the lungs of chronically infected patients with CF.

Chronic lung infection with Pseudomonas aeruginosa is the most severe complication in patients with cystic fibrosis (CF). ${ }^{1}$ The thick viscous endobronchial mucus hampers mucociliary clearance, which renders the CF lungs susceptible to chronic infections. ${ }^{2}$ The chronic $P$ aeruginosa lung infection in patients with CF is characterised by endobronchial mucoid biofilms surrounded by numerous polymorphonuclear leucocytes (PMNs). ${ }^{3}{ }^{4}$ In spite of the bactericidal mechanisms of the PMNs and aggressive antibiotic treatments, the biofilms persist. $P$ aeruginos a may obtain protection against the PMNs by formation of mucoid biofilm. ${ }^{1}$ Thus, instead of clearing the bacteria the PMNs are suspected to promote progressive lung tissue deterioration by releasing proteolytic enzymes and reactive oxygen species (ROS) responsible for premature death in CF. ${ }^{15}$ Even though PMNs with evidence of priming and phagocytic activity have been isolated from CF airways, the activity of $\mathrm{PMNs}$ in the lungs of patients with $\mathrm{CF}$ with chronic $P$ aeruginosa lung infection is far from being resolved. ${ }^{5}$ Interestingly, anaerobic conditions in the mucus have recently been demonstrated in nonobstructed bronchi of patients with CF with chronic $P$ aeruginosa lung infection. ${ }^{3}$ The cause of this $\mathrm{O}_{2}$ depletion may be $\mathrm{O}_{2}$ consumption by the epithelia and by $P$ aeruginosa. ${ }^{3}$ We hypothesised that the respiratory burst of the PMNs contributes to the $\mathrm{O}_{2}$ consumption in the mucus of the infected CF airways. The interaction between bacteria and the PMNs may increase $\mathrm{O}_{2}$ consumption as a consequence of the extra respiration during phagocytosis. ${ }^{6}$ This process is caused by the respiratory burst resulting from the one-electron reduction of $\mathrm{O}_{2}$ by the phagocyte NADPH oxidase (Phox) to $\mathrm{O}_{2}{ }^{7}$. To evaluate the capability of the respiratory burst to deplete $\mathrm{O}_{2}$, we constructed a simple reaction chamber that allowed real-time measurement of the $\mathrm{O}_{2}$ concentration during phagocytosis of $P$ aeruginosa by PMNs. The respiratory burst was isolated from aerobic respiration by blocking the respiratory chain with $\mathrm{KCN}$, which previously has been employed to demonstrate the resistance of the respiratory burst to inhibition of the aerobic respiration in PMNs. ${ }^{8}$ The aerobic respiratory component was exposed by inhibiting the Phox with diphenylene iodonium (DPI). These in vitro findings were utilised to estimate the $\mathrm{O}_{2}$ consumption and the ROS production by the respiratory burst of the PMNs in freshly expectorated sputum from patients with CF with chronic $P$ aeruginosa lung infection.

\section{METHODS \\ Sputum samples}

The study was performed on leftover sputum expectorated for routine bacteriology from 29 patients with CF with chronic $P$ aeruginosa infections after obtaining permission by informed consent.

Chronic $P$ aeruginosa infection was defined as the presence of $P$ aeruginosa in the lower respiratory tract at each monthly culture for $\geqslant 6$ months, or for a shorter time in the presence of increased antibody response to $P$ aeruginosa ( $\geqslant 2$ precipitating antibodies, normal: 0-1). ${ }^{9}$ Before measurement of luminol-enhanced chemiluminescence (LEC) and dissolved $\mathrm{O}_{2}$, the samples were brought into 
Table I Characteristics of the 29 patients with cystic fibrosis

\begin{tabular}{ll}
\hline Characteristic & \\
\hline Sex $(\mathrm{M} / \mathrm{F})$ & $15 / 14$ \\
Age $($ years) & $32(22-47)$ \\
Duration of chronic infection (years) & $19(1-35)$ \\
FEV $_{1}(\%)^{*}$ & $48(23-117)$ \\
FVC $(\%)^{*}$ & $89(58-135)$ \\
During intravenous antibiotic treatment & 21 \\
In between intravenous antibiotic treatment & 8 \\
\hline
\end{tabular}

*Values are medians (range).

$\mathrm{F}$, female; $\mathrm{FEV}_{1}$, forced expiratory volume in $1 \mathrm{~s} ; \mathrm{FVC}$, forced vital capacity; $\mathrm{M}$, male.

homogenous suspensions by gentle resuspension with a pipette. Normoxic conditions were achieved by diluting 10 times with Krebs-Ringer buffer equilibrated in ambient air. The concentration of leucocytes in the diluted sputum was determined as previously described. ${ }^{10}{ }^{11}$ The estimation of the frequency of $\mathrm{PMNs}$ is described in online supplementary fig 5.

\section{Preparation of PMNs}

Human blood samples were obtained from normal healthy volunteers by venous puncture and the PMNs were isolated by gradient sedimentation and centrifugation, as previously described, before suspending the PMNs in Krebs-Ringer buffer with $10 \mathrm{mM}$ glucose and 5\% (v/v) normal human AB-positive sera at a density of $5 \times 10^{9} \mathrm{PMNs} / 1 .^{10}{ }^{11}$

\section{Bacteria}

Inoculum for phagocytosis by $\mathrm{PMNs}$ was prepared from exponentially growing cultures of the widely studied $P$ aeruginosa wild-type strain (PAO1) (online supplementary fig 1).

\section{Estimation of the respiratory burst by LEC}

The LEC from aliqouts of $100 \mu$ of isolated PMNs or sputum was determind as outlined in online supplementary fig 3 .

\section{The concentration of dissolved $\mathbf{O}_{2}$}

Measurement of dissolved $\mathrm{O}_{2}$ in sputum and during phagocytosis is described in online supplementary fig 2.

\section{Visualiaation of $\mathbf{0}_{2}^{-}$production}

Hydroethidine (HE) (D7008, Sigma, St Louis, Missouri, USA) at $1 \mu \mathrm{M}$ was added to $100 \mu \mathrm{l}$ of sputum and the samples were incubated for $15 \mathrm{~min}$ at $37^{\circ} \mathrm{C}$ before examination with a fluorescence microscope (BX40, Olympus, Ballerup, Denmark). To verify the origin of $\mathrm{O}_{2}^{-}$, sputum was pretreated for $10 \mathrm{~min}$ with $50 \mu \mathrm{M}$ DPI before addition of $\mathrm{HE}$. The interaction between PMNs and bacteria in the sputum samples was visualised by adding $\mathrm{HE}(1 \mu \mathrm{M})$ together with the green permeable DNA dye SYTO 9 (Molecular Probes, Eugene, Oregon, USA) $(10 \mu \mathrm{M})$, and the samples were incubated for $15 \mathrm{~min}$ at $37^{\circ} \mathrm{C}$ before examination.

\section{Statistical methods}

Statistical significance was evaluated by two-way analysis of variance (ANOVA) with Bonferroni post-tests for observations with parametric data. Non-parametric data were analysed by Wilcoxon signed rank test and Spearman rank correlation test. A $p$ value $<0.05$ was considered statistically significant. The tests were performed with Prism 4.0c (GraphPad Software, La Jolla, California, USA).

\section{RESULTS}

$\mathbf{O}_{\mathbf{2}}$ consumption by PMNs and $\boldsymbol{P}$ aeruginosa during phagocytosis Estimations of the $\mathrm{O}_{2}$ consumption during phagocytosis were initiated at atmospheric $\mathrm{O}_{2}$ concentration. Accelerated initial $\mathrm{O}_{2}$ consumption with a reduced $\mathrm{O}_{2}$ consumption rate at low $\mathrm{O}_{2}$ concentrations was seen when mixing PMNs with PAO1 (fig 1A). Nevertheless, the $\mathrm{O}_{2}$ concentration decreased below the level of detection $\left(0.01 \mathrm{mg} \mathrm{O}_{2} / \mathrm{l}\right)$. This was considered as an indication of anaerobic conditions, since similar recordings were obtained in buffer equilibrated in an anaerobic bench with growing strict anaerobes as control. Low $\mathrm{O}_{2}$ consumption by unstimulated PMNs was also seen (fig 1A). Evidence of phagocytosis was provided by the reduced number of surviving $P$ aeruginosa in the presence of PMNs (online supplementary fig 1) and by the green fluorescent protein (GFP)-tagged $P$ aeruginosa being ingested by or attached to the PMNs in the reaction chamber (online supplementary fig 2 ).

The $\mathrm{O}_{2}$ consumption of $P$ aeruginosa resulted in anaerobic conditions within $2 \mathrm{~h}$ (fig $1 \mathrm{~B}$ ) and indicated that $P$ aeruginosa may consume a considerable part of the $\mathrm{O}_{2}$ during phagocytosis.

\section{Inhibition of the respiratory burst with DPI during phagocytosis of $\boldsymbol{P}$ aeruginosa by PMNs}

Treatment with $50 \mu \mathrm{M}$ DPI reduced the chemiluminescence, which predominantly reflects $\mathrm{O}_{2}^{-}$production during phagocytosis, to the level of unstimulated PMNs for up to $50 \mathrm{~min}$ (online supplementary fig $3 \mathrm{~A}$ ). Thus, inhibition of the respiratory burst with $50 \mu \mathrm{M}$ DPI during phagocytosis resulted in reduced $\mathrm{O}_{2}$ consumption and prevention of anaerobic conditions (fig 1A). Since treatment with $50 \mu \mathrm{M}$ DPI did not affect bacterial $\mathrm{O}_{2}$ consumption (fig $1 \mathrm{~B}$ ), growth, and survival after phagocytosis (online supplementary fig 1) significantly, $50 \mu \mathrm{M}$ DPI was selected for estimating the $\mathrm{O}_{2}$ consumption by the respiratory burst of the PMNs.

\section{Inhibition of the respiratory chain with KCN during phagocytosis of $\boldsymbol{P}$ aeruginosa by PMNs}

Unexpectedly, the LEC was increased (online supplementary fig 3B) without affecting the $\mathrm{O}_{2}$ concentration (fig 1A) during phagocytosis inhibited with $\mathrm{KCN}$. This could not be ascribed to $P$ aeruginosa since the bacteria ceased to consume $\mathrm{O}_{2}$ shortly after addition of $2 \mathrm{mM} \mathrm{KCN} \mathrm{(fig} 1 \mathrm{~B}$ ). Instead, the surprisingly high $\mathrm{O}_{2}$ consumption and LEC during $\mathrm{KCN}$ treatment may result from a higher amount of $\mathrm{O}_{2}$ being available for the respiratory burst due to the bacteria failing to consume $\mathrm{O}_{2}$. In addition, $\mathrm{KCN}$ repression of aerobic respiration may decrease bacterial motility and facilitate capture of $P$ aeruginosa by the $\mathrm{PMN}$, resulting in a stronger respiratory burst. Though $\mathrm{KCN}$ treatment may overestimate the $\mathrm{O}_{2}$ consumption by the respiratory burst, it was decided to use $2 \mathrm{mM} \mathrm{KCN}$ for the study of sputum. Lower concentrations may be insufficient to block the pseudomonal cyanide-independent terminal oxidase. ${ }^{12}$

\section{$\mathbf{O}_{2}$ consumption by the respiratory burst in sputum from patients with CF with chronic $\boldsymbol{P}$ aeruginosa lung infection}

To ensure similar initial $\mathrm{O}_{2}$ concentrations, the expectorated sputum was diluted 10 times in Krebs-Ringer buffer equilibrated in ambient air. $\mathrm{O}_{2}$ consumption was observed in all sputum samples by the decreasing $\mathrm{O}_{2}$ concentration, and anaerobic conditions were established in 10 of the 23 sputum samples (fig 2A). The chemiluminescence was inhibited $>95 \%$ after 10 min of treatment with DPI whereas KCN treatment had no effect (online supplementary fig 4). Thus, the sputum 

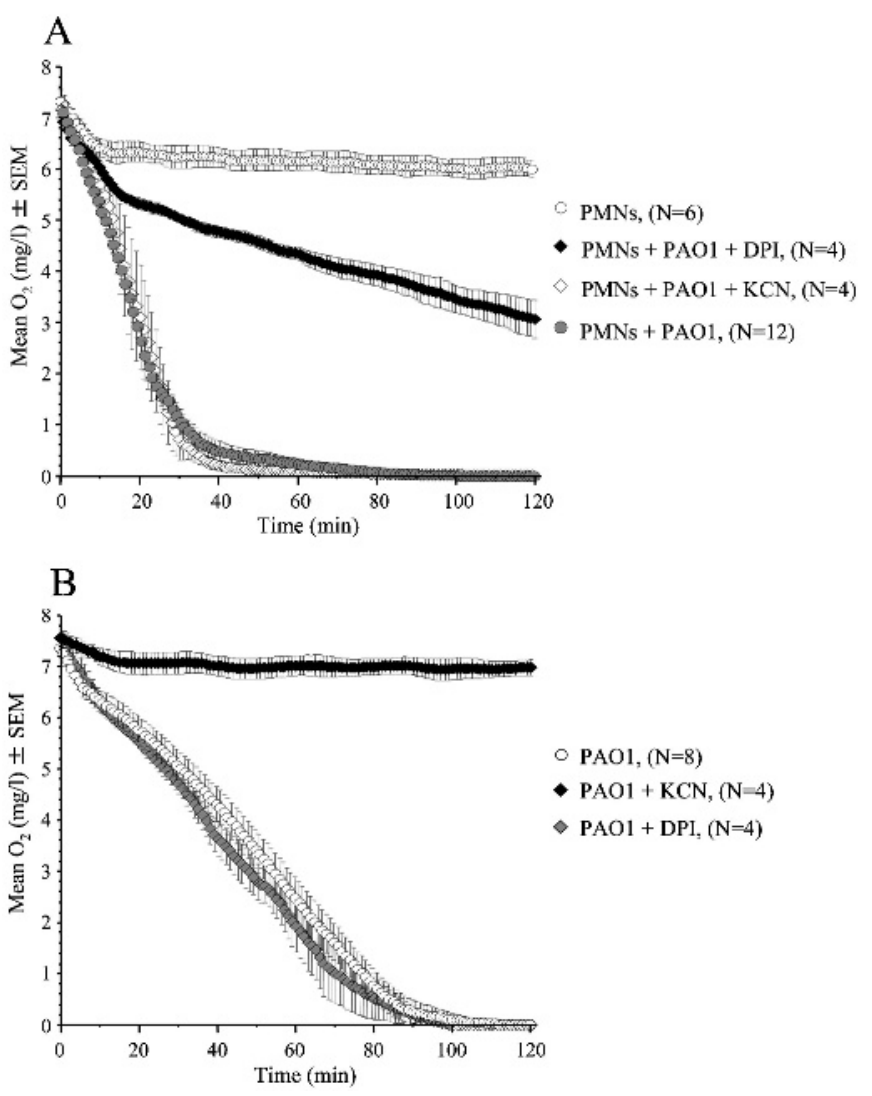

Figure $1 \quad \mathrm{O}_{2}$ consumption by the respiratory burst and aerobic respiration in the reaction chamber. $(A)$ Increased $\mathrm{O}_{2}$ consumption during phagocytosis $(p<0.001)$, inhibition of the respiratory burst during phagocytosis by treatment with $50 \mu \mathrm{M}$ diphenylene iodonium (DPI) $(p<0.001)$, and unchanged $\mathrm{O}_{2}$ consumption during phagocytosis by treatment with $2 \mathrm{mM} \mathrm{KCN}$ during phagocytosis of strain PA01 $(15 \times 10 \%$ I) by normal polymorphonuclear leucocytes $(\mathrm{PMNs})\left(5 \times 10^{9} / \mathrm{I}\right)$. (B) Decreased $\mathrm{O}_{2}$ consumption by PA01 $\left(15 \times 10^{9} / \mathrm{l}\right)$ during treatment with $2 \mathrm{mM} \mathrm{KCN}(\mathrm{p}<0.001)$ and unaffected bacterial $\mathrm{O}_{2}$ consumption during treatment with $50 \mu \mathrm{M}$ DPI. Statistical analysis was performed by twoway analysis of variance.

was pretreated with DPI and KCN for 10 min to estimate the $\mathrm{O}_{2}$ consumption rate during the following $30 \mathrm{~min}$ before the $\mathrm{O}_{2}$ was depleted. The $\mathrm{O}_{2}$ consumption rate was reduced by DPI treatment, indicating an active respiratory burst in the sputum samples, and resulted in a mean inhibition of the $\mathrm{O}_{2}$ consumption rate by $56 \%$ (SD 20\%) (fig $2 \mathrm{~B}$ ), suggesting that the respiratory burst consumed the major part of the $\mathrm{O}_{2}$. Active $\mathrm{O}_{2}$ consumption by the respiratory chain was also observed by the reduced $\mathrm{O}_{2}$ consumption rate caused by addition of KCN (fig 2C). The consequence of inhibiting the respiratory burst with DPI was a delayed generation of anaerobic conditions (fig 2D) whereas inhibition of the respiratory chain with KCN was insufficient to delay the depletion of $\mathrm{O}_{2}$ significantly. DPI treatment allowed us to detect comparable levels of the $\mathrm{O}_{2}$ consumption rate by the burst per PMN in CF sputum and in the phagocytosis experiment using normal PMNs and PAO1. In the sputum we found $1.7 \mathrm{nmol} \mathrm{O} / 10^{6} \mathrm{PMNs} / \mathrm{min}(\mathrm{SD} 1.6 \mathrm{nmol} \mathrm{O} /$ $10^{6} \mathrm{PMNs} / \mathrm{min}$ ) and in the experimental phagocytosis assay we found $1.5 \mathrm{nmol} \mathrm{O}_{2} / 10^{6} \mathrm{PMNs} / \mathrm{min}$ (SD $0.4 \mathrm{nmol} \mathrm{O}_{2} / 10^{6} \mathrm{PMNs} /$ min). These data make it unlikely that the $\mathrm{O}_{2}$ consumption rate of sputum PMNs is a CF-specific phenomenon.
PMNs with respiratory burst in sputum from patients with CF with chronic $\boldsymbol{P}$ aeruginosa lung infection

The mean fraction of PMNs constituted $90 \%$ (7\%) (SD) of the host cells in the sputum samples. Therefore, the concentration of PMNs was compared with the $\mathrm{O}_{2}$ consumption rate in the diluted sputum samples. A positive correlation was observed, supporting the involvement of PMNs in the $\mathrm{O}_{2}$ consumption (fig 3A). Positive correlations were also observed between the concentration of colony-forming units (CFUs) and the $\mathrm{O}_{2}$ consumption rate (fig $3 \mathrm{~B}$ ) and between the concentration of PMNs and the concentration of CFUs (fig 3C). No significant correlation was observed between the $\mathrm{O}_{2}$ consumption rate and forced expiratory volume in $1 \mathrm{~s}\left(\mathrm{FEV}_{1}\right)$ or forced vital capacity (FVC).

To avoid unintended effects of the Krebs-Ringer buffer, the respiratory burst in undiluted sputum samples was estimated by LEC. As in diluted sputum, DPI treatment resulted in $>95 \%$ inhibition after $10 \mathrm{~min}$ in undiluted sputum (fig 4A), indicating an active respiratory burst that persisted during the $2 \mathrm{~h}$ of observation. Furthermore, the LEC was resistant to KCN, suggesting an origin that may function independently of the respiratory chain such as the Phox of the PMNs. ${ }^{8}$ To verify further the PMNs as the source of ROS in sputum, $\mathrm{O}_{2}$ production was visualised by staining with $\mathrm{HE}$, which is oxidised by $\mathrm{O}_{2}$ to generate 2-hydroxyethidium that emits intensified red fluorescence when complexing with DNA. ${ }^{13}$ In the untreated sputum, several fluorescent objects were seen at low magnification. Higher magnification revealed these objects to be PMNs (fig 4B). In DPI-treated sputum, only faint fluorescence was seen (fig 4C). By applying the validated HE to fresh, expectorated sputum together with the permeable DNA stain, SYTO 9, we found bursting PMNs with ingested planktonic bacteria (fig 4D) and bursting PMNs failing to engulf bacteria from a biofilm (fig 4E).

\section{DISCUSSION}

PMNs in bronchoalveolar lavage fluids from chronically infected patients with CF and in sputum from healthy individuals have the potential to mount a respiratory burst upon stimulation. ${ }^{14}{ }^{15}$ In contrast, the presence of PMNs with an active respiratory burst was demonstrated in fresh sputum from patients with CF with chronic $P$ aeruginosa lung infection in this study. Both the inhibition of $\mathrm{O}_{2}$ consumption and ROS generation with DPI as well as the correlation of the PMN concentration to the $\mathrm{O}_{2}$ consumption rate are indications of an ongoing respiratory burst by the PMNs in sputum from chronically infected patients with CF. PMNs with an active respiratory burst were not demonstrated directly in the lungs of the patients in this study. Therefore, our findings do not necessarily reflect the situation of all PMNs in the endobronchial mucus of infected CF lungs since the $\mathrm{pO}_{2}$ may differ at various sites in the sputum plugs. However, the rapid, high chemiluminescence, observed in undiluted sputum ex vivo, may exclude the possibility that adding Krebs-Ringer buffer, equilibrated to ambient air, causes the oxidative burst. In this context, the initial, high $\mathrm{O}_{2}$ consumption and ROS generation seen in untreated sputum samples within $30 \mathrm{~min}$ after expectoration suggest that the respiratory burst of the PMNs was already active in the mucus in the lungs. Thus, our results indicate that the respiratory burst of the PMNs is the main contributor to the intensive $\mathrm{O}_{2}$ depletion inside the mucus of the bronchi. ${ }^{3}$ The respiratory burst of the PMNs in the sputum may be activated by direct contact with $P$ aeruginos $a^{5}{ }^{16}$ and by the binary signalling from the engagement of the integrins and binding to inflammatory cytokines. ${ }^{17}$ Interestingly, we have recently found levels of 

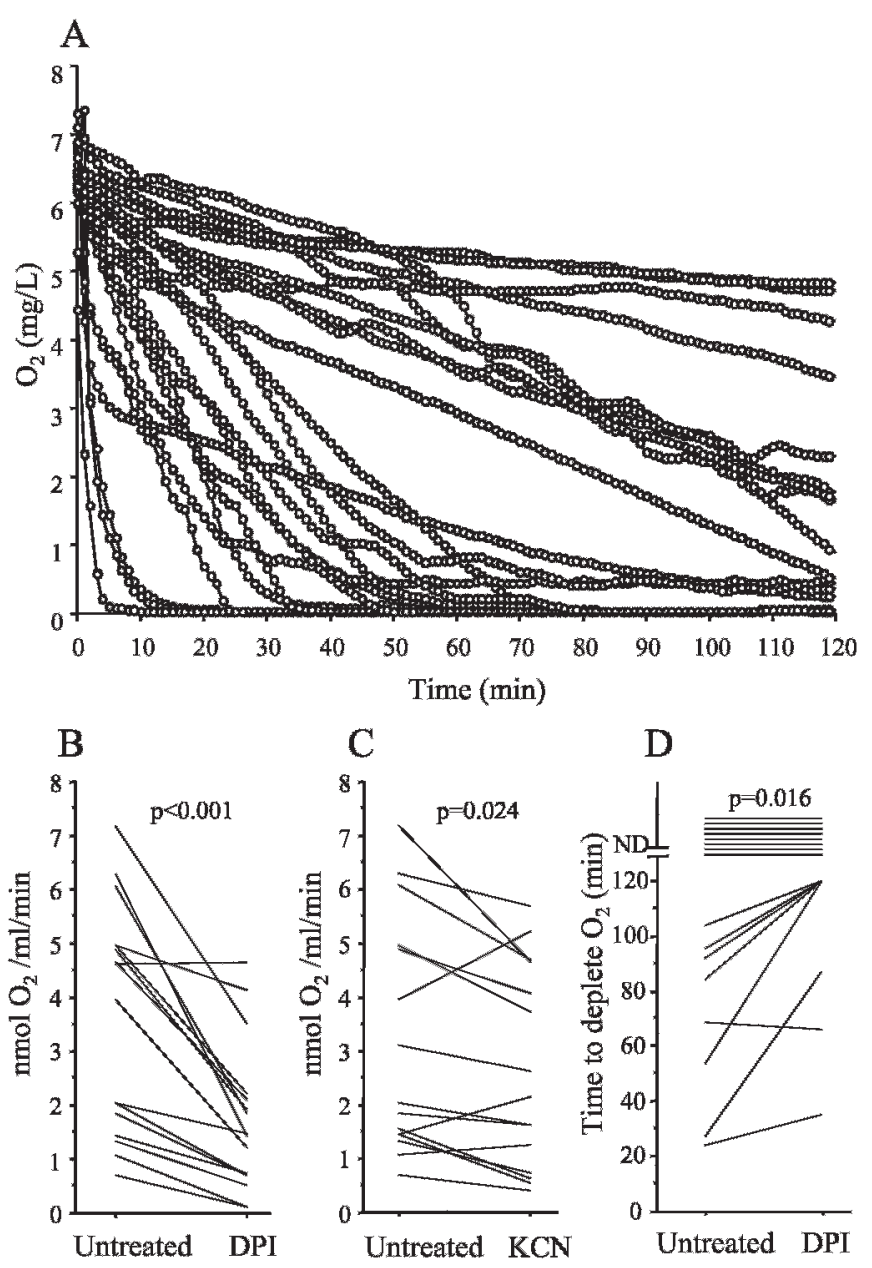

Figure $2 \quad \mathrm{O}_{2}$ consumption and reactive oxygen species generation in diluted sputum from patients with cystic fibrosis with chronic $P$ aeruginosa lung infection. (A) The decreasing $\mathrm{O}_{2}$ concentration as a function of incubation time measured in the reaction chamber $(n=23)$. (B) Reduced $\mathrm{O}_{2}$ consumption rate in sputum treated with $50 \mu \mathrm{M}$ diphenylene iodonium (DPI) $(n=16)$. (C) Reduced $\mathrm{O}_{2}$ consumption rate in sputum treated with $2 \mathrm{mM} \mathrm{KCN}(\mathrm{n}=15)$. (D) Postponing of $\mathrm{O}_{2}$ depletion in sputum treated with $50 \mu \mathrm{M}$ DPI. In B-D, data were analysed by Wilcoxon signed rank test.

tumour necrosis factor $\alpha(T N F \alpha)$ with the potential to augment the respiratory burst in sputum from several infected patients with CF attending the Copenhagen CF Centre, as in the patients in the present study. ${ }^{18}$ In addition, comparable levels of TNF $\alpha$ in sputum from infected patients with CF are reported from other CF centres. ${ }^{19}$ Besides TNF $\alpha$, platelet-activating factor, leukotriene B4, interleukin-8, lipopolysaccharide, antibodies and alginate have been suggested to be major triggers for the induction of the respiratory burst of airway PMNs. ${ }^{15} 1819$ In contrast, the respiratory burst of the PMNs may be repressed by quorum sensing-regulated secretion of rhamnolipid, by exoprotease from $P$ aeruginosa, by antibiotic treatment and by the high levels of apoptotic or necrotic cells in the sputum samples. ${ }^{10}{ }^{11} 20-22$ These opposing mechanisms may contribute to the variation observed in the correlation between the concentration of PMNs and the $\mathrm{O}_{2}$ consumption in the sputum. Our results imply that at least in some parts of the CF mucus $\mathrm{O}_{2}$ is present, which allows PMNs to create a respiratory burst. This is in accordance with the steep $\mathrm{pO}_{2}$ gradients in CF mucus. ${ }^{3}$ Furthermore, based on the substantial fraction of PMNs able to create a significant respiratory burst found in CF sputum in this study, our previous demonstrations of
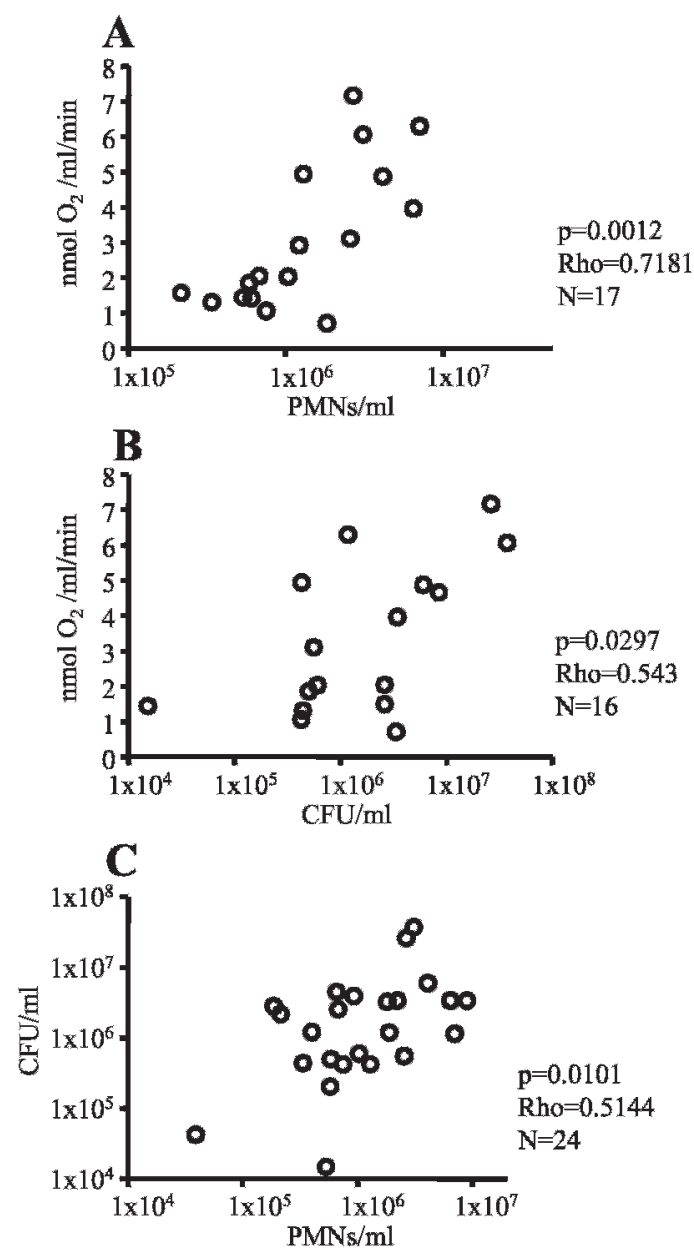

Figure 3 Correlations between the $\mathrm{O}_{2}$ consumption rate, the concentration of polymorphonuclear leucocytes (PMNs) and colonyforming units (CFUs) in diluted sputum from patients with cystic fibrosis with chronic $P$ aeruginosa lung infection. The $\mathrm{O}_{2}$ consumption rate was determined in the reaction chamber, the concentration of PMNs was estimated by flow cytometry, and the CFUs were counted by plating of serial dilutions. (A) $\mathrm{O}_{2}$ consumption rate vs the concentration of PMNs. (B) $\mathrm{O}_{2}$ consumption rate vs the concentration of CFUs. (C) The concentration of PMNs vs the concentration of CFUs. Statistical analysis was performed by Spearman rank correlation test.

the toxic effects of $P$ aeruginosa rhamnolipid on PMNs may not apply to the entire population of PMNs in the sputum. ${ }^{10}{ }^{11}$

The demonstration of PMNs with an active respiratory burst in sputum from chronically infected patients with CF may have been anticipated due to the ROS lesions in the infected CF lungs. ${ }^{53}$ However, it could not have been taken for granted. In fact, the ROS in the CF lungs may be derived from sources other than the Phox of the PMNs, including epithelial cells, alveolar macrophages, and from mitochondrial respiration. ${ }^{23-25}$ Due to the predominance of PMNs in the sputum samples the contribution of other cells to $\mathrm{O}_{2}$ metabolism was regarded to have low impact on the results in this study. In contrast to the Phox, mitochondrial activity is unlikely to influence significantly our observations in the sputum samples. PMNs contain only few and poorly developed mitochondria with a low activity of the respiratory chain. ${ }^{26}$ In addition, sputum from chronically infected patients with CF may contain $P$ aeruginosa producing pyocyanine, which may also cause $\mathrm{O}_{2}^{-}$formation. ${ }^{27}$ Thus, $\mathrm{O}_{2}^{-}$formation by pyocyanine may be a reason why DPI failed to block ROS generation completely in the sputum samples. 


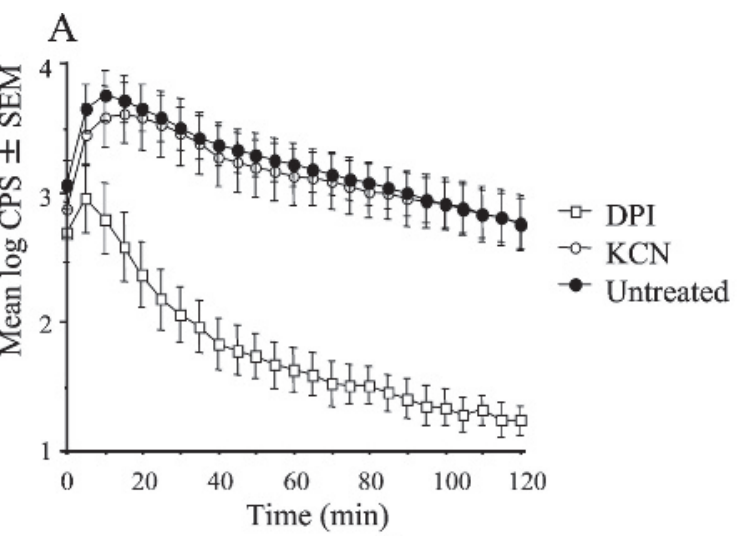

B

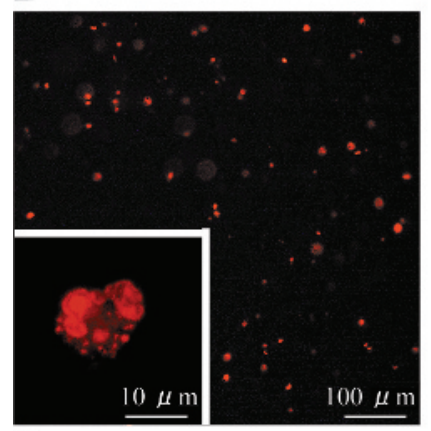

$\mathrm{D}$

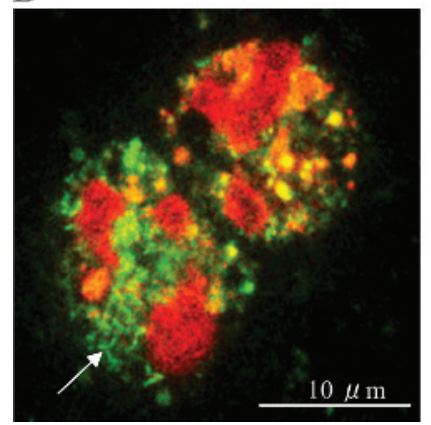

$\mathrm{C}$

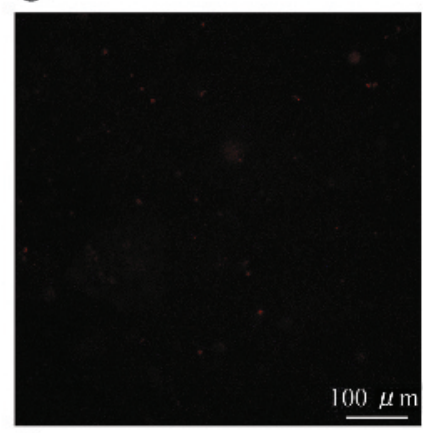

E

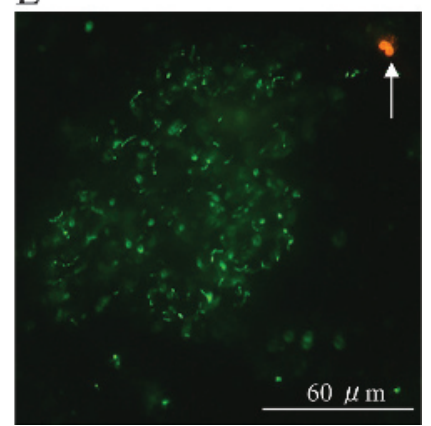

Figure 4 Reactive oxygen species (ROS) generation in sputum from patients with cystic fibrosis with chronic $P$ aeruginosa lung infection. (A) The effect of treatment with KCN and inhibition with diphenylene iodonium (DPI) $(p<0.001)$ on ROS generation shown as counts per second (CPS) from luminol-enhanced chemiluminescence $(n=10)$. Statistical analysis was performed by two-way analysis of variance $(\mathrm{n}=10)$. (B-E) Visualisation of $\mathrm{O}_{2}$ production by fluorescence microscopy of sputum stained with hydroethidine. (B) Untreated sputum. (C) Sputum treated with $50 \mu \mathrm{M}$ DPI to inhibit the phagocyte NADPH oxidase. (D) Polymorphonuclear leucocytes (PMNs) with ingested planktonic bacteria (arrow) with green fluorescence from SYTO 9. (E) A bursting PMN (arrow) engaged with a biofilm with bacteria emitting green fluorescence from SYTO 9.

Previously, faster $\mathrm{O}_{2}$ depletion has been achieved when PMNs were added to $P$ aeruginosa growing in experimental biofilms due to increased $\mathrm{O}_{2}$ consumption of both the bacteria and the PMNs. ${ }^{16}$ However, in the present study the ability of the PMNs per se to create anaerobic conditions by an active respiratory burst was observed in the $\mathrm{KCN}$-resistant $\mathrm{O}_{2}$ depletion during the phagocytosis of PAO1 and in the sputum samples. This may, however, be expected, since PMNs are able to produce a substantial part of the energy needed for the respiratory burst by anaerobic glycolysis resulting in L-lactate formation. ${ }^{28}$ Accordingly, our suggestion of an active respiratory burst by the PMNs in the CF lungs is supported by the increased glucose uptake in PMNs in CF lungs

and the high concentration of L-lactate in sputum from patients with CF with chronic $P$ aeruginosa lung infection. ${ }^{29} 30$

The demonstration of PMNs with an active respiratory burst in sputum samples from patients with CF with chronic $P$ aeruginosa lung infection verifies the frequent assumption that the PMNs induce ROS lesions in the lungs. Sufficient $\mathrm{O}_{2}$ to produce $\mathrm{O}_{2}^{-}$by the respiratory burst of the PMNs in sputum may be supplied by the daily inhalation of 8000 litres of $\mathrm{O}_{2}$-rich air. ${ }^{23}$ The result of the fast dismutation of $\mathrm{O}_{2}^{-}$is $\mathrm{H}_{2} \mathrm{O}_{2}$, which may lead to the formation of myeloperoxidase-derived oxidising species found in CF airways. ${ }^{5}$ Considering the short half-lives of the ROS generated by PMNs, the tissue adjacant to the mucus is most likely to be exposed to PMN-derived ROS. Therefore, ROS generated in the mucus may be a reason for the affected bronchi in patients with CF with chronic $P$ aeruginosa lung infection. ${ }^{31}$ However, it is less obvious how ROS generated in the mucus may reach more distant lung tissue. Since the included patients with CF show a broad range of $\mathrm{FEV}_{1}$ values, one may suggest that the $\mathrm{O}_{2}$ consumption rate might be linked to pulmonary function in these patients. However, no significant correlation was observed between the $\mathrm{O}_{2}$ consumption rate and $\mathrm{FEV}_{1}$ or FVC. This may be due to the condition of the infected patients, which has been stabilised for years by elective antibiotic treatment, resulting in a slower decline of lung function and fewer excerbations. Thus, the lung function of the included patients may primarily result from slowly accumulated deterioations of the lung tissue rather than the ongoing inflammation in the endobronchial mucus. Our results provide arguments to control the extent of ROS by antibiotic treatment, since $\mathrm{O}_{2}$ consumption was mainly caused by ROS formation of the $\mathrm{PMN}$ and was correlated to the concentration of $P$ aeruginosa in the sputum samples. The latter correlation probably results from a balanced accumulation of PMNs in response to the concentration of $P$ aeruginosa in the sputum samples.

As indicated in fresh sputum samples, the ROS from the respiratory burst of the PMNs in the mucus may reach the bacteria, due to their ingestion by $\mathrm{PMNs}$, with a respiratory burst and the intimate surrounding of the endobronchial biofilms by the PMNs. ${ }^{4}$ Though the killing of $P$ aeruginosa by PMNs was apparently independent of ROS formation in this study, the surviving bacteria may experience ROS lesions, which may affect virulence. In particular, PMN-derived ROS may cause mutations in the mucA gene, leading to formation of the crucial mucoid phenotypes. ${ }^{32}$ In fact, mutations in the mucA gene were found in the majority of the mucoid isolates from 91 Scandinavian patients with chronic $P$ aeruginosa infection. ${ }^{33}$ In addition, the PMN-derived ROS may induce highly mutagenic lesions in the bacterial DNA that are associated with resistance to antibiotics and accumulation of hypermutable isolates. ${ }^{34}$

The accelerated $\mathrm{O}_{2}$ depletion by the PMNs probably affects the $\mathrm{O}_{2}$ distribution in the endobronchial mucus. Though the precise $\mathrm{O}_{2}$ profile of the endobronchial mucus has not been determined, the activity of the PMNs is sensitive to the local $\mathrm{O}_{2}$ tension. In particular, the accumulation of PMNs in the lung secretions may be increased due to the postponing of apoptosis by hypoxia. ${ }^{35}$

Sputum from chronically infected patients with CF may also contain biomarkers for the bacterial response to $\mathrm{O}_{2}$ depletion such as slow growth and cyanide secretion. ${ }^{12} 36$

This study demonstrates an ongoing respiratory burst of the PMNs in sputum from patients with CF with chronic $P$ aeruginosa lung infection that may induce environmental changes in the lungs with the potential to generate virulent and resistant bacterial phenotypes, to facilitate colonisation by anaerobic bacteria and to cause oxidative lesions in the lung tissue of the patients. 
Acknowledgements: The skilful assistance of Marjan Yousefi, Louise Falk-Lauritsen and Lars Kolpen is gratefully appreciated and recognised as being crucial for this study.

Funding: None.

Competing interests: None.

Provenance and peer review: Not commissioned; externally peer reviewed.

\section{REFERENCES}

1. Koch C, Høiby N. Pathogenesis of cystic fibrosis. Lancet 1993:341:1065-9.

2. Knowles MR, Boucher RC. Mucus clearance as a primary innate defense mechanism for mammalian airways. J Clin Invest 2002;109:571-7.

3. Wörlitzsch D, Tarran R, Ulrich M, et al. Effects of reduced mucus oxygen concentration in airway Pseudomonas infections of cystic fibrosis patients. J Clin Invest 2002; 109:317-25.

4. Bjarnsholt T, Jensen PØ, Fiandaca MJ, et al. Pseudomonas aeruginosa biofilms in the respiratory tract of cystic fibrosis patients. Pediatr Pulmonol 2009;44:547-58.

5. Downey DG, Bell SC, Elborn JS. Neutrophils in cystic fibrosis. Thorax 2009;64:81-8.

6. Baldridge CW, Gerard RW. The extra respiration of phagocytosis. Am J Physiol 1933;103:235-6.

7. Babior BM, Curnuttte JT, McMurrich BJ. The particulate superoxide-forming system from human neutrophils. Properties of the system and further evidence supporting its participation in the respiratory burst. J Clin Invest 1976;58:989-96.

8. Sbarra AJ, Karnovsky ML. The biochemical basis of phagocytosis. I. Metabolic changes during the ingestion of particles by polymorphonuclear leukocytes. $J$ Biol Chem 1959;234:1355-62.

9. Høiby N. Microbiology of cystic fibrosis. In: Hodson ME, Geddes DM, eds. Cystic fibrosis. 2nd edn. London, UK: Arnold, 2000:83-107.

10. Bjarnsholt T, Jensen PØ, Burmølle $\mathrm{M}$, et al. Pseudomonas aeruginosa tolerance to tobramycin, hydrogen peroxide and polymorphonuclear leukocytes is quorum-sensing dependent. Microbiology 2005;151:373-83.

11. Jensen PØ, Bjarnsholt T, Phipps R, et al. Rapid necrotic killing of polymorphonuclear leukocytes is caused by quorum-sensing-controlled production of rhamnolipid by Pseudomonas aeruginosa. Microbiology 2007;153:1329-38.

12. Williams HD, Zlosnik JEA, Ryall B. Oxygen, cyanide and energy generation in the cystic fibrosis pathogen Pseudomonas aeruginosa. Adv Microbial Phys 2007;52:1-71.

13. Zhao $\mathbf{H}$, Joseph J, Fales HM, et al. Detection and characterization of the product of hydroethidine and intracellular superoxide by HPLC and limitations of fluorescence. Proc Natl Acad Sci USA 2005;102:5727-32.

14. Roum JH, Borok Z, McElvaney NG, et al. Glutathione aerosol suppresses lung epithelial surface inflammatory cell-derived oxidants in cystic fibrosis. J Appl Physiol 1999;87:438-43.

15. Alexis N, Soukup J, Ghio A, et al. Sputum phagocytes from healthy individuals are functional and activated: a flow cytometric comparison with cells in bronchoalveolar lavage and peripheral blood. Clin Immunol 2007:97:21-32.

16. Jesaitis AJ, Franklin MJ, Berglund D, et al. Compromised host defense on Pseudomonas aeruginosa biofilms: characterization of neutrophil and biofilm interactions. J Immunol 2003;171:4329-39.

17. Nathan C, Srimal S, Farber C, et al. Cytokine-induced respiratory burst of human neutrophils: dependence on extracellular matrix proteins and CDU/CD18 integrins. J Cell Biol 1989;109:1341-9.
18. Jensen Pø, Moser C, Kharazmi A, et al. Increased serum concentration of G-CSF in cystic fibrosis patients with chronic Pseudomonas aeruginosa pneumonia. J Cyst Fibros 2006;5:145-51

19. Jones AM, Martin L, Bright-Thomas RJ, et al. Inflammatory markers in cystic fibrosis patients with transmissible Pseudomonas aeruginosa. Eur Respir J 2003;22:503-6.

20. Kharazmi A, Høiby N, Döring G, et al. Pseudomonas aeruginosa exoproteases inhibit human neutrophil chemiluminescence. Infect Immun 1984;44:587-91.

21. Umeki S. Anti-inflammatory action of gentamycin through inhibitory effect on neutrophil NADPH oxidase activity. Comp Biochem Physiol B Biochem Mol Biol 1995; 110:817-21.

22. Watt AP, Courtney J, Moore J, et al. Neutrophil cell death, activation and bacterial infection in cystic fibrosis. Thorax 2005;60:659-64.

23. Cantin AM, White TB, Cross CE, et al. Antioxidants in cystic fibrosis. Conclusions from the CF antioxidant workshop, Bethesda, Maryland, November 11-12, 2003. Free Radic Biol Med 2007;42:15-31.

24. van der Vliet A. NADPH oxidases in lung biology and pathology: host defense enzymes, and more. Free Radic Biol Med 2008;44:938-55.

25. Calhoun WJ, Bates ME, Schrader L, et al. Enhanced superoxide production by alveolar macrophages and air-space cells, airway inflammation, and alveolar macrophage density changes after segmental antigen bronchoprovocation in allergic subjects. Am Rev Respir Dis 1992;145:317-25.

26. Maianski NA, Geissler J, Srinivasula SM, et al. Functional characterization of mitochondria in neutrophils: a role restricted to apoptosis. Cell Death Differ 2004;11:143-53.

27. Gardner PR. Superoxide production by the mycobacterial and pseudomonad quinoid pigments phthiocol and pyocyanine in human lung cells. Arch Biochem Biophys 1996;333:267-74.

28. Borregaard $\mathbf{N}$, Herlin T. Energy metabolism of human neutrophils during phagocytosis. J Clin Invest 1982;70:550-7.

29. Chen DL, Ferkol TW, Mintun MA, et al. Quantifying pulmonary inflammation in cystic fibrosis with positron emission tomography. Am J Respir Crit Care Med 2006;173:1363-9.

30. Wörlitzsch D, Bensel T, Borneff-Lipp M, et al. Pseudomonas aeruginosa and lactate in vitro and in CF sputum. Pediatr Pulmonol 2007;S30:317.

31. Wiebe BM, Burton CM, Milman N, et al. Morphometric examination of native lungs in human lung allograft recipients. APMIS 2006;114:795-804.

32. Mathee K, Ciofu O, Sternberg C, et al. Mucoid conversion of Pseudomonas aeruginosa by hydrogen peroxide: a mechanism for virulence activation in the cystic fibrosis lung. Microbiology 1999;145:1349-57.

33. Ciofu 0, Riis B, Pressler $\mathrm{T}$, et al. Occurrence of hypermutable Pseudomonas aeruginosa in cystic fibrosis patients is associated with the oxidative stress caused by chronic lung inflammation. Antimicrob Agents Chemother 2005;49:2276-82.

34. Ciofu 0, Lee B, Johannesson M, et al. Investigation of the algT operon sequence in mucoid and non-mucoid Pseudomonas aeruginosa isolates from 115 Scandinavian patients with cystic fibrosis and in 88 in vitro non-mucoid revertants. Microbiology 2008;154:103-13.

35. Hannah S, Mecklenburgh K, Rahman I, et al. Hypoxia prolongs neutrophil survival in vitro. FEBS Lett 1995;372:233-7.

36. Yang L, Haagensen JAJ, Jelsbak $L$, et al. In situ growth rates and biofilm development of Pseudomonas aeruginosa populations in chronic lung infections. J Bacteriol 2008;190:2767-76. 